\title{
MINERAIS CONTAMINANTES DO CAULIM DA MINA IPIXUNA, NO ESTADO DO PARÁ: CARACTERÍSTICAS E INTERFERÊNCIAS NO BENEFICIAMENTO MINERAL
}

\author{
S. SABEDOT'; R. M. KAUTZMANN ${ }^{2}$; C. O. PETTER ${ }^{3}$ e C. H. SAMPAIO ${ }^{4}$ \\ ${ }^{1}$ Curso de Mestrado Avaliação de Impactos Ambientais - UNILASALLE \\ sabedot@unilasalle.edu.br \\ ${ }^{2}$ Curso de Mestrado Avaliação de Impactos Ambientais - UNILASALLE \\ rubensm@unilasalle.edu.br \\ ${ }^{3}$ Laboratório de Processamento Mineral - UFRGS \\ cpetter@ufrgs.br \\ ${ }^{4}$ Laboratório de Processamento Mineral - UFRGS \\ sampaio@ufrgs.br
}

Artigo submetido em novembro/2013 e aceito em dezembro/2013

DOI: http://dx.doi.org/10.15628/holos.2014.1749

\section{RESUMO}

A mina Ipixuna extrai caulim sedimentar e produz matéria-prima final para a indústria do papel. 0 minério varia devido a presença de minerais contaminantes. Whiteness, yellowness e composição química são parâmetros importantes no processamento mineral. Visualmente, minério com cor vermelha ou amarela é descartado, e com cor clara é aproveitado. Nesta pesquisa, as análises com espectrofotometria, estereomicroscopia e mineralogia com amostras de minério mostraram que a mineralogia contaminante é um indicador importante na tomada de decisão sobre o beneficiamento. Verificou-se que blocos com cor amarela e com alto teor de ferro, podem gerar produto final com qualidade para o papel, quando o principal mineral contaminante é a goethita, removida na separação magnética e branqueamento no químico.

PALAVRAS-CHAVE: caulim, espectrofotometria, mineralogia, processamento.

\section{MINERAL CONTAMINANTS OF KAOLIN FROM IPIXUNA MINE, PARÁ STATE: CHARACTERISTICS AND INTERFERENCES IN THE MINERAL PROCESSING}

\begin{abstract}
The Ipixuna Mine extracts sedimentary kaolin and produces final raw material for the paper industry. The ore varies due to the mineral contaminants content. Whiteness, yellowness and chemical composition are important parameters in mineral processing. Visually, ore with red or yellow color is refused, and whitish materials are classified as economic ones. A study considering spectrophotometry, stereomicroscopy and mineralogy
\end{abstract}

with all varieties from the ore deposit showed that the mineralogy contaminant is an important indicator in deciding which ore blocks should or should not be processed. This study showed that yellowish blocks with high iron content can generate final raw material with quality for the paper industry, when the main contaminant is goethite, which can be removed in the magnetic separation and chemical bleaching processes.

KEYWORDS: petroleum, environmental risks, drilling rig, the risk maps. 


\section{INTRODUÇÃO}

A mina Ipixuna localiza-se na região do rio Capim, município de Ipixuna do Pará, estado do Pará. É explorada pela empresa Imerys Rio Capim Caulim S/A, que produz caulim de qualidade para a indústria de papel. A Amazônia Ocidental tem importantes jazidas de caulim e a região do rio Capim é considerada como a maior reserva mundial de caulim atualmente em produção. A geologia da mina é definida por uma Unidade Inferior, correspondendo a uma topo-sequência de perfil laterítico derivado da Formação Ipixuna, e uma Unidade Superior constituída por sedimentos da Formação Barreiras. É atribuída idade Cretácea Superior aos sedimentos, os quais se encontram depositados na bacia do Parnaíba. O caulim ocorre na Formação Ipixuna e se distribui em três fácies: caulim arenoso na base, caulim macio na zona intermediária e caulim flint (também denominado semi-flint) no topo (COSTA et al., 2009; MUSSEL et al., 2008 ; MURRAY et al., 2007; ROSSETI e SANTOS Jr., 2006; KOTSCHOUBEY et al., 1996). O caulim macio é o principal nível de minério extraído e beneficiado pelas empresas que atuam na região (CARNEIRO et al., 2003), por apresentar características físicas e mineralógicas mais apropriadas no uso como cobertura para papel. A caulinita é o mineral predominante (SOUSA et al., 2006), ocorrendo uma assembleia de minerais contaminantes, como o quartzo, hematita, goethita e anatásio, entre outros.

Whiteness (índice de alvura) e yellowness (índice de amarelamento) do concentrado de caulim são parâmetros importantes quando esta matéria-prima é utilizada na indústria de papel, especialmente para cobertura; alto whiteness e baixo yellowness determinam maior valor comercial (YANIK, 2011; VARELA et al., 2005; BLOODWORTH et al., 1993). O caulim ROM (run-ofmine) geralmente contém minerais contaminantes que precisam ser removidos nos processos de beneficiamento (RAITANI et al., 2012; RAGHAVAN, 2010), que incluem dispersão, desareamento, centrifugação, separação magnética e branqueamento químico para gerar um caulim (produto final) de alta alvura.

O minério contém variações texturais e mineralógicas horizontais e verticais na jazida. Os blocos para a lavra devem apresentar quantidades de minerais contaminantes possíveis de serem removidos no beneficiamento, de modo a gerar um produto final economicamente viável. Em geral, a cor do bloco é determinante na escolha: blocos com cores vermelhas ou amarelas são rejeitados por conterem hematita, goethita e/ou anatásio em excesso, o que dificulta suas remoções no beneficiamento; cores claras (esbranquiçadas) são indicativas de baixas concentrações de contaminantes. Se os resultados de análises químicas, alvura e yellowness do bloco de cor clara estiverem dentro de valores pré-determinados pelos engenheiros da mina, o mesmo pode ser lavrado e beneficiado.

Amostras de minério ROM foram coletadas em diferentes locais e profundidades na mina Ipixuna e beneficiadas em bancada, simulando o processo industrial. Produtos e rejeitos decorrentes foram analisados quanto as suas características físicas, químicas, mineralógicas e colorimétricas. Sabedot et al. (2011) definiram, com base nos resultados colorimétricos, sete grupos espectrofotométricos de minério ROM e indicaram os grupos adequados e inadequados à produção de um produto final com qualidade para a indústria de papel, bem como sugeriram situações de blendagens entre os grupos. No atual estudo, acrescentam-se informações sobre as características mineralógicas dos grupos espectrofotométricos e que interferem no beneficiamento mineral. 


\section{MATERIAL E MÉTODOS}

Foram coletadas três amostras para cada um dos cinco tipos de minério ROM existentes na jazida, de acordo com os parâmetros econômicos ou não, indicados pelos engenheiros da empresa, totalizando 15 amostras. Cada amostra, com cerca de uma tonelada, foi beneficiada em plantapiloto na empresa, com a aplicação de uma rota de beneficiamento tradicional para este tipo de minério: dispersão, desareamento, centrifugação, separação magnética, branqueamento químico, filtragem e secagem. Alíquotas de produtos e rejeitos de cada etapa do beneficiamento foram remetidas para o Laboratório de Processamento Mineral (LAPROM), da UFRGS, para diversos estudos.

Amostras de ROM e de produtos e rejeitos do beneficiamento foram analisadas em espectrofotômetro da marca Minolta, modelo 2600d, na faixa de comprimento de onda entre 360 a $740 \mathrm{~nm}$; também foram analisadas em estereomicroscópio binocular, onde identificaram-se texturas, cores, estruturas e fases características, e em difratômetro de raios x para a identificação da mineralogia, com a aplicação dos procedimentos TOD (deposição) e TOC (calcinação).

\section{RESULTADOS E DISCUSSÃO}

\subsection{Espectrofotometria}

Os conjuntos de espectros de reflectância das 15 amostras foram classificados em sete grupos colorimétricos de caulim, considerando-se as curvas de reflectância dos produtos do beneficiamento em cada amostra. A Figura 1 mostra os espectros padrão dos grupos, considerando dois produtos e um rejeito.

O Produto Desareado serviu como ponto de partida do estudo colorimétrico. Este produto é mais adequado que o ROM, por conter quartzo e contaminantes grossos em menor quantidade; o Produto Final é a matéria-prima obtida com o beneficiamento; o Rejeito da Separação Magnética é formado por minerais contaminantes magnéticos, especialmente hematita, goethita e anatásio.

Aliados aos valores de alvura, yellowness e concentração de $\mathrm{Fe}_{2} \mathrm{O}_{3}$ e $\mathrm{TiO}_{2}$ (SABEDOT et al., 2011) os espectros indicam que quatro grupos podem ser considerados economicamente viáveis à produção de caulim com qualidade para papel (Grupos I, II, III e VI) e três grupos não são recomendados para beneficiamento (Grupos IV, V e VII). O formato convexo das curvas Produto Final nos Grupos I, II, III e VI, especialmente na faixa de comprimento de onda 360 e $500 \mathrm{~nm}$, indica que houve redução dos minerais contaminantes com o beneficiamento para valores aceitáveis no Produto Final; os valores de alvura nos Produtos Finais variaram de 86,1 a $89,5 \%$. Nas curvas Produto Final dos Grupos IV e V há uma inflexão em torno do comprimento de onda $450 \mathrm{~nm}$, indicando que os processos não removeram com eficácia os minerais contaminantes de cor vermelha; as alvuras finais variaram entre 70,4 e $80,3 \%$. O Grupo VII corresponde a uma variedade de caulim arenoso cujo ROM contém altas concentrações dos óxidos de Fe e Ti e elevada quantidade de quartzo; a presença massiva deste mineral define uma textura diferenciada para esta variedade de minério, em relação às demais consideradas neste estudo. Com o beneficiamento, a curva Produto Final do Grupo VII apresenta convexidade semelhante às curvas dos grupos considerados economicamente viáveis. No entanto, a alvura $83,4 \%$ é baixa para o 
Produto Final, porque os minerais que contêm os óxidos de Fe e Ti não foram removidos com eficácia para gerar uma matéria-prima final de qualidade para a indústria de papel.
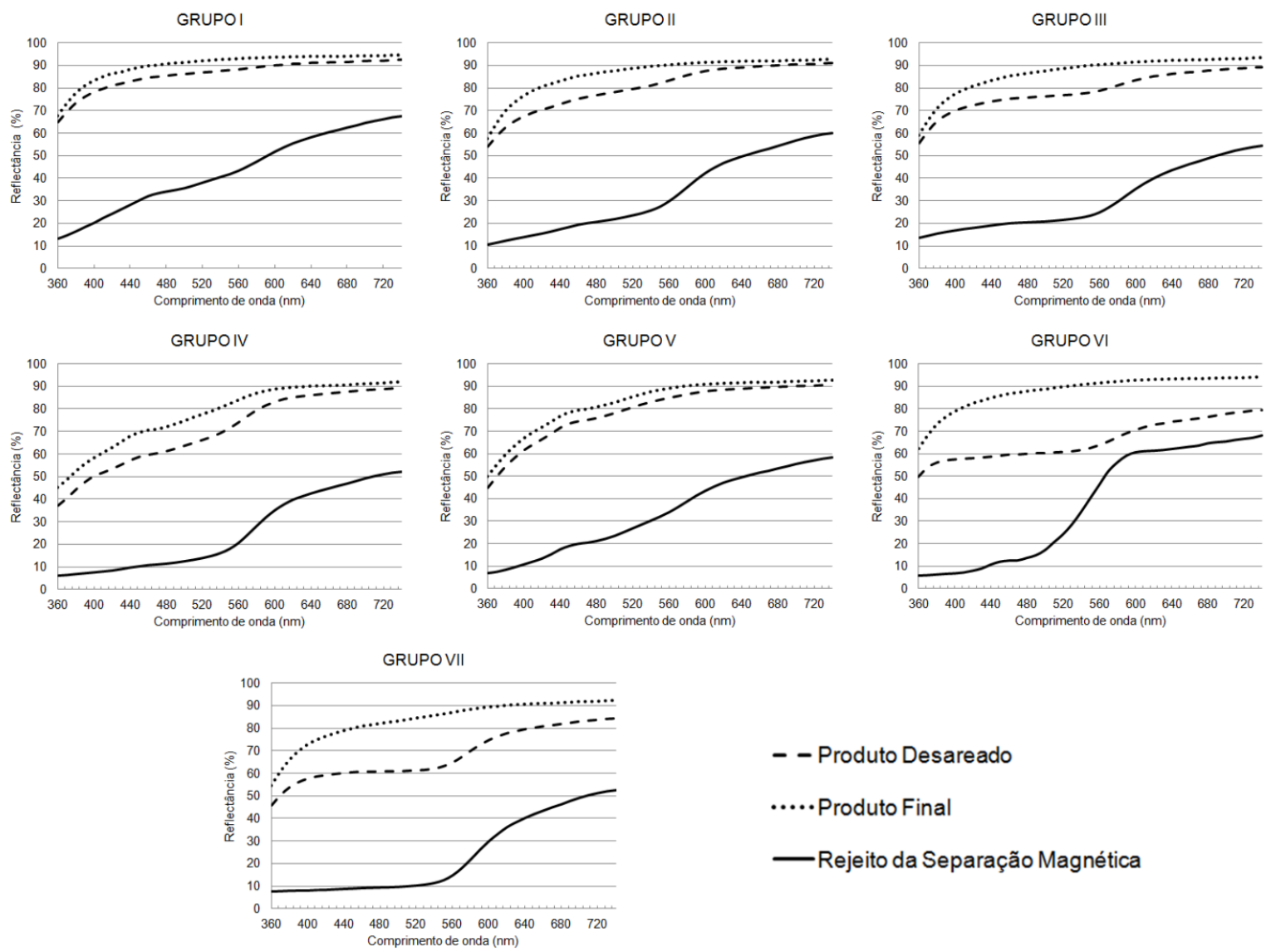

Figura 1 - Grupos colorimétricos de caulim da mina Ipixuna.

\subsection{Estereomicroscopia}

As amostras das variedades de caulim ora se apresentam friáveis, ora estão em blocos pouco coesos e se destacam pela variada coloração, que vai do branco, amarelo, vermelho ao roxo. A sequência sedimentar indica um ambiente gerador de baixa energia onde predominam lamitos, podendo ter níveis de siltitos e areia fina.

A variedade de cores chama a atenção e indica que a distribuição do ferro no perfil é o principal vetor das mudanças de coloração nas amostras. Coletaram-se subamostras nas amostras que continham cores variadas para um estudo específico da textura e mineralogia contida.

O material de cor vermelha está estruturado em lâminas milimétricas por vezes cortadas por vênulas também milimétricas de material branco contendo quartzo transparente, arredondado, alguns com faces angulares. No material vermelho não se oberva quartzo.

O material de cor amarela tem textura friável e é composto por areia e poucos fragmentos arredondados de argila. Os fragmentos de argila são coesos e possuem até cinco centímetros de diâmetro e alguns grãos de quartzo com tamanho silte são identificados na matriz argilosa. A porção areia é formada por grãos de quartzo fracamente ligados por uma matriz argilosa, com 
cores que variam do amarelo ao branco; são bem selecionados, pouco arredondados e muito quebradiços.

No material de cor cinza os grãos são coesos e massivos. Observam-se pontuações pretas dispersas, mas que também formam bandas centimétricas. $O$ bandamento fica ressaltado devido a diferenças na coloração, com níveis de tons de branco e outros de cor escura e que conferem à subamostra uma cor cinza no aspecto macro. Finos grãos de quartzo estão presentes, mas sua identificação é dificultada por estarem dispersos na matriz argilosa.

No material de cor roxa os fragmentos são coesos e têm laminações, que ao detalhe, mostram variações no tamanho dos grãos. A estrutura em lâminas origina-se do processo de sedimentação em que as laminações com granulação mais grossa estariam relacionadas com um ambiente de energia mais elevado e as laminações mais finas se depositariam em ambiente com menor energia, formado predominantemente por argila, cuja análise estereomicroscópica não evidenciou a presença de quartzo.

\subsection{Difratometria}

Nos difratômetros das subamostras brancas e coloridas os principais picos correspondem à caulinita, com picos secundários de muscovita e quartzo.

No material vermelho aparecem picos de goethita e hematita no procedimento TOD. No procedimento TOC a goethita é decomposta ressaltando hematita e anatásio; quartzo não é identificado. O difratômetro das vênulas de cor branca ressalta o pico de anatásio no procedimento TOC, mas não se identifica nenhuma fase cristalina com ferro.

Nos fragmentos argilosos do material amarelo o pico para anatásio é ressaltado no procedimento TOC; não apareceu evidência de fases cristalinas com ferro. Entretanto, na fase arenosa deste material não foi detectado anatásio no procedimento TOC. Há indicações de que o anatásio tem um posicionamento preferencial na porção pelítica, mais rica em caulinita.

As bandas claras e escuras do material de cor cinza foram analisadas e os resultados foram semelhantes, provavelmente devido à dificuldade de se coletar material distinto em ambas as bandas. No procedimento TOC o anatásio está presente e não se detectou hematita em ambos os materiais. Comprova-se, novamente, a relação do anatásio com a fração caulinítica predominante.

No material de cor roxa os resultados foram semelhantes em ambas as bandas de granulometria mais grossa e mais fina. No procedimento TOD, além da caulinita, observa-se a presença subordinada de quartzo, muscovita e hematita. O procedimento TOC ressalta o anatásio e confirma hematita e muscovita em ambas as bandas.

\subsection{Os minerais contaminantes e os grupos colorimétricos de caulim}

Gonçalves e Petter (2007) e Gonçalves (2009) desenvolveram uma técnica para determinação da concentração de contaminantes de caulim através da teoria de Kubelka-Munk. Nestes estudos os autores afirmam que o tamanho da partícula é o principal fator na determinação das propriedades colorimétricas dos minerais. Concentraram hematita, goethita e anatásio de diversas amostras de minério da mina Ipixuna e definiram seus espectros de reflectância (Figura 2); estabeleceram dois espectros para anatásio (fino e grosso), dois espectros para hematita (fina, 
com cor vermelha e grossa, com cor roxa) e um espectro para goethita, devido ao fato de não encontrarem variabilidade significativa nos espectros de grãos finos e grossos deste mineral.

Os estudos aqui referenciados têm por objetivo a definição de procedimentos simples e de operação rápida para identificar variedades de minério mais adequadas à produção de matériaprima final de qualidade, através dos espectros de reflectância. Na mina, diferentes variedades de minério extraídas de diversas frentes de lavra que são blendadas em pilhas e processadas. Devido aos diversos minerais contaminantes presentes no minério, especialmente os de cor vermelha, amarela e preta e suas concentrações, considera-se que o tempo de processamento e uso de reagentes químicos podem ser otimizados, evitando-se blendagens entre algumas variedades.

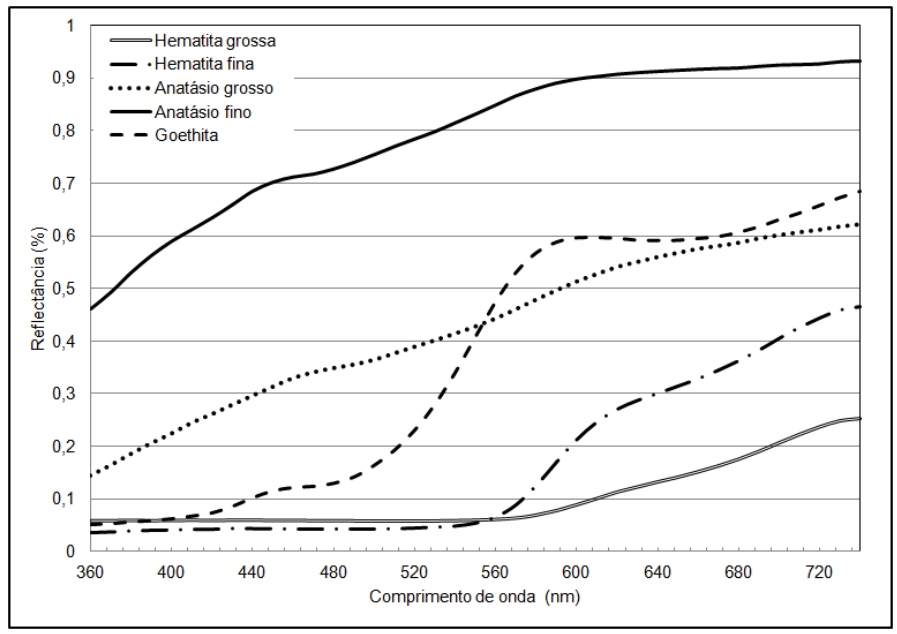

Figura 2 - Espectros de reflectância dos principais minerais contaminantes coloridos da mina Ipixuna. Fonte: Gonçalves (2009), modificado.

Os espectros da Figura 2 foram comparados com os espectros dos rejeitos da separação magnética dos grupos colorimétricos da Figura 1, numa tentativa de se estabelecer alguma analogia entre os formatos dos espectros e a mineralogia contaminante nos grupos. No Grupo I, fica evidente que o principal contaminante é o anatásio grosso. No Grupo II, o espectro do Rejeito da Separação Magnética se assemelha mais ao espectro do anatásio grosso. Entretanto, a leve concavidade próxima ao comprimento de onda $560 \mathrm{~nm}$ no espectro do Rejeito da Separação Magnética do Grupo II é indicativa da presença de hematita, o que sugere que a forma deste espectro é uma combinação de anatásio com hematita, mas com forte influência do primeiro mineral. As análises químicas dos produtos desareados das amostras deste Grupo indicaram uma proporção aproximada de 2:1 entre $\mathrm{TiO}_{2}$ e $\mathrm{Fe}_{2} \mathrm{O}_{3}$, respectivamente. No Grupo III, a forma do espectro do Rejeito da Separação Magnética não mostra similaridade com nenhum espectro da Figura 2. As análises químicas dos produtos desareados indicaram uma proporção de 1:1 entre $\mathrm{TiO}_{2}$ e $\mathrm{Fe}_{2} \mathrm{O}_{3}$, respectivamente; neste caso, sugere-se que a forma do espectro no Grupo III seja fortemente influenciada pela presença de hematita, considerando-se a inclinação da curva na faixa 400-550 nm, característica deste mineral, com menor influência do anatásio. No Grupo IV, o espectro do Rejeito da Separação Magnética também não mostra similaridade com os espectros da Figura 2. Percebe-se uma ligeira semelhança com o espectro da hematita grossa, evidenciando a influência deste mineral no rejeito; nas análises químicas, o teor de $\mathrm{Fe}_{2} \mathrm{O}_{3}$ no Grupo IV é de duas a três vezes maior do que nos Grupos I, II e III, e o teor de $\mathrm{TiO}_{2}$, em média, é menor. Visualmente, 
a cor do minério ROM deste Grupo é vermelha e os processos de beneficiamento geraram produtos finais de baixa alvura e alto yellowness. A marcante presença de hematita indica que esta variedade de ROM é inadequada à produção de matéria-prima para o mercado de papel. No Grupo V, o espectro do Rejeito da Separação Magnética mostra similaridade com o espectro do anatásio grosso da Figura 2. Nas análises químicas, o teor de $\mathrm{TiO}_{2}$ é cerca de $40 \%$ superior ao teor de $\mathrm{Fe}_{2} \mathrm{O}_{3}$, e ambos os valores dos óxidos estão muito acima dos limites desejáveis para a produção de matéria-prima de boa qualidade, o que influenciou nos resultados ruins para alvura e yellowness. Associando estes dados à cor visual do ROM, marrom-avermelhado, a variedade que constitui o Grupo V não deve ser destinada ao beneficiamento. No Grupo VI, o espectro do Rejeito da Separação Magnética mostra correspondência com o espectro da goethita da Figura 2. Esta variedade apresenta as seguintes características: a cor visual do ROM tem forte tonalidade amarelo-avermelhado; o teor de $\mathrm{Fe}_{2} \mathrm{O}_{3}$ no Produto Desareado é 2,82\%, muito acima dos teores para o mesmo produto nos demais grupos e muito acima do limite aceitável para o beneficiamento; a alvura no Produto Desareado é $59,4 \%$ e o yellowness é $15,5 \%$. Essas informações sugerem que a variedade é inadequada para o beneficiamento, sendo descartada quando identificada. Uma característica positiva é o teor de $\mathrm{TiO}_{2}(0,82 \%)$, o menor entre os sete grupos. Neste estudo, após seu processamento em planta-piloto, os resultados do Produto Final foram muito interessantes: o teor de $\mathrm{Fe}_{2} \mathrm{O}_{3}$ baixou para $0,35 \%$; o teor de $\mathrm{TiO}_{2}$ baixou para $0,75 \%$; a alvura subiu para $87,4 \%$; o yellowness baixou para $6,8 \%$. Estes dados conferem ao Produto Final do Grupo VI qualidade similar ao mesmo produto do Grupo I, considerado o de melhor qualidade para a indústria do papel, neste estudo. No Grupo VII, o espectro do Rejeito da Separação Magnética mostra similaridade com o espectro da hematita fina da Figura 2. Os teores de $\mathrm{Fe}_{2} \mathrm{O}_{3}$ e $\mathrm{TiO}_{2}$ no Produto Desareado são altos (1,14 e 1,61\%, respectivamente) e se mantiveram no Produto Final. Devido à alta concentração de quartzo, esta variedade é descrita por Criscuolo (2008) como arenito caulinítico, que apresenta reologia inadequada e granulometria grossa, características que inviabilizam seu aproveitamento econômico.

\section{CONCLUSÕES}

As variedades de cores do minério de caulim da mina Ipixuna resultam da ocorrência e concentração de minerais contaminantes, especialmente hematita, goethita, anatásio e quartzo. Tendo como base a classificação em grupos colorimétricos (SABEDOT et al., 2011) e os estudos aqui apresentados, conclui-se que a cor vermelha resulta da mistura entre hematita e goethita, em quantidades equivalentes; diferentes proporções entre os dois minerais podem resultar na cor marrom. A cor amarela indica a presença de goethita. A cor cinza (tonalidade clara) é o resultado da combinação de cores branca e cinza (tonalidade escura) de finas camadas milimétricas a centimétricas interestratificadas, de caulinita com baixas e altas concentrações de anatásio. A cor roxa resulta da presença do contaminante hematita.

Considerando os estudos de Gonçalves (2009) e os resultados da avaliação química e espectrofotométrica dos rejeitos da separação magnética das 15 amostras, neste estudo, concluiuse que: os resultados espectrofotométricos do Grupo I foram influenciados pela presença de anatásio grosso; dos Grupos II e III, pela presença dos minerais anatásio e hematita, porém com a influência mais forte deste último mineral; do Grupo IV, pela presença da hematita; do Grupo V, pela presença do anatásio grosso; do Grupo VI, pela presença da goethita; e do Grupo VII, pela presença da hematita. 
Para o melhor aproveitamento econômico da jazida e a viabilidade para o melhor rendimento operacional, considerando-se o contexto dos grupos colorimétricos, conclui-se, também, que o minério do Grupo I deva ser extraído e beneficiado sem blendagem com os outros grupos; que os minérios dos Grupos II e III podem ser processados de modo individual ou blendados entre si em qualquer proporção; que o minério do Grupo VI deva ser extraído e processado sem blendagem com os demais grupos.

Os resultados deste estudo, em consonância com os demais aqui referenciados, mostram que a definição da mineralogia contaminante é um indicador adequado para as tomadas de decisão nas operações de extração e processamento de blocos de minério, visando à obtenção de matéria-prima final de qualidade à indústria do papel; especialmente, quando se analisam os resultados do minério classificado como Grupo VI.

\section{REFERÊNCIAS BIBLIOGRÁFICAS}

1. BLOODWORTH, A.J., HIGHLEY, D.E., MITCHELL, C.J. Industrial Minerals Laboratory annual: Kaolin. United Kingdom: British Geological Survey. Technical Report WG/93/1, Mineralogy and Petrology Series. 80 p., 1993.

2. CARNEIRO, B.S., ANGÉLICA, R.S., SCHELLER, T., CASTRO, E.A.S., NEVES, R.F. Caracterização mineralógica e geoquímica e estudo das transformações de fase do caulim duro da região do Rio Capim, Pará. Cerâmica, 49, p. 237-244, 2003.

3. COSTA, M.L., SOUSA, D.J.L., ANGÉLICA, R.S. The contribution of lateritization processes to the formation of the kaolin deposits from eastern Amazon. Journal of South American Earth Sciences, v. 27(2-3), p. 219-234, 2009.

4. CRISCUOLO, P.S.R. Beneficiamento do caulim duro das bacias dos rios Capim e Jari através do processo de agregação seletiva. Dissertação de Mestrado, UFMG - Universidade Federal de Minas Gerais, Belo Horizonte, 2008.

5. GONÇALVES, I.G. Determinação da concentração de contaminantes no caolim através da teoria de Kubelka-Munk. Dissertação de Mestrado. PPGEM, UFRGS, 2009.

6. GONÇALVES, I.G., PETTER, C.O. Kubelka-Munk theory applied to industrial minerals: prediction of impurity content in kaolin. REM Revista Escola de Minas, v.60(3), p. 491-496, 2007.

7. KOTSCHOUBEY B., TRUKENBRODT W., HIERONYMUS B. Depósitos de caolim e argila semi-flint no nordeste do Pará. Revista Brasileira de Geociências, v. 26(2), p. 71-80, 1996.

8. MURRAY, H.H., ALVES, C.A., BASTOS, C.H. Mining, processing and applications of the Capin Basin kaolin, Brazil. Clay Minerals, v. 42(2), p. 145-151, 2007.

9. MUSSEL, W.N., MURAD, E., CRISCUOLO, P.S.R., PINHEIRO, P.G., FABRIS, J.D. Variation of mineralogy during the beneficiation of Capim kaolin from Pará, Brazil. Clay Minerals, v. 43(3), p. 381-391, 2008.

10. RAGHAVAN, P. Technology development for kaolin processing. Proceedings of the XI International Seminar on Mineral Processing Technology (MPT-2010), NML Jamshedpur, India, 2010.

11. RAITANI, R., JIANG, S., BHATNAGAR, A., RAVISHANKAR, S.A. Chemically echanced magnetic separation technologies for kaolin processing. Minerals \& Metallurgical Processing, v.29(1), p. 
20-26, 2012.

12. ROSSETI, D.F., SANTOS JR, A.E.A. Analysing the origin of the Upper Cretaceous-Lower Tertiary Rio Capim semi flint (Pará State, Brazil) under a sedimentologic perspective. Sedimentary Geology, v. 186(1-2), p. 133-144, 2006.

13. SABEDOT, S., PETTER, C.O., SAMPAIO, C.H. Espectrocolorimetria de variedades de caulim da Jazida Ipixuna, no Estado do Pará. REM, Revista da Escola de Minas, 64(3), p. 363-368, 2011.

14. SOUSA, D.J.L., VARAJÃO, A.F.D.C., YVON, J. Geochemical evolution of the Capim River kaolin, Northern Brazil. Journal of Geochemical Exploration, 88, p. 329-331, 2006.

15. VARELA, J.J., GLIESE, R., PETTER, C.O., PEIXOTO, C.A. Controle de qualidade no processamento de polpas de caulim utilizando propriedades óticas. REM Revista Escola de Minas, v.58(3), p. 201-206, 2005.

16. YANIC, G. Mineralogical, crystallographic and technological characteristics of Yaylauolu kaolin (Kütahya, Turkey). Clay Minerals. V.46(3), p. 397-410, 2011. 